\title{
Cardioprotective Effects of Wharton Jelly Derived Mesenchymal Stem Cell Transplantation in a Rodent Model of Myocardial Injury
}

\author{
Taghrid Gaafar ${ }^{1}$, Wael Attia ${ }^{2}$, Shereen Mahmoud ${ }^{1}$, Dina Sabry ${ }^{3}$, \\ Osama Abdel Aziz ${ }^{2}$, Dina Rasheed ${ }^{1}$, Hala Hamza ${ }^{2}$ \\ Departments of ${ }^{1}$ Clinical Pathology, ${ }^{2}$ Pediatric Cardiology, ${ }^{3}$ Biochemistry, Faculty of Medicine, Cairo University, Cairo, Egypt
}

Background: Whartons jelly-derived mesenchymal stem cells are a valuable alternative source that possess multipotent properties, easy to obtain and available in large scale compared to BMMSCs. We investigated the possibility of cardiac function improvement post isoproterenol induced cardiac injury in a rat model following human WJMSCs transplantation.

Materials and Methods: MSCs were extracted and cultured from cord WJ, characterized by morphology, Immunophenotyping and differentiation to osteoblast and adipocytes. WJMSCs were labeled with PKH2 linker dye. Wistar rats were divided into control group, ISO group (injected with 2 doses of isoproterenol) to induce myocardial injury and ISO group transplanted with labelled WJMSCs. ECG, electrocardiographic patterns, cardiac marker enzymes, tracing of labeled MSCs and immunohistochemical analysis of myocardial cryosections were studied.

Results and Conclusions: WJ derived MSCs were expanded for more than 14 passages while maintaining their undifferentiated state, were positive for MSC markers and were able to differentiate into adipocyte and osteoblast. We demonstrated that intravenously administered WJMSCs were capable of homing predominently in the ischemic myocardium. Cardiac markers were positively altered in stem cell treated group compared to ISO group. ECG and ECHO changes were improved with higher survival rate. WJMSCs could differentiate into cardiac-like cells (positive for cardiac specific proteins) in vivo. WJMSCs infusion promoted cardiac protection and reduced mortality, emphasizing a promising therapeutic role for myocardial insufficiency.

Keywords: Mesenchymal stem cells, Isoproterenol, Transplantation, Wharton's jelly, Cardiac repair

\section{Introduction}

Cell therapy has emerged as a promising alternative to treat chronic diseases. Regenerative and reparative thera-

\footnotetext{
Accepted for publication February 4, 2017, Published online May 30, 2017 Correspondence to Taghrid Gaafar

Clinical and Chemical Pathology Department (Stem Cell Research unit), Faculty of Medicine, Cairo University, Cairo, Egypt

Tel: +2-01223106418, Fax: +2022526991

E-mail: tagrid8@yahoo.com

(c) This is an open-access article distributed under the terms of the Creative Commons Attribution Non-Commercial License (http://creativecommons.org/ licenses/by-nc/4.0/), which permits unrestricted non-commercial use, distribution, and reproduction in any medium, provided the original work is properly cited.

Copyright (c) 2017 by the Korean Society for Stem Cells Research
}

pies would be particularly important for heart disease since, despite many recent advances in medical therapy and interventional techniques, ischemic heart disease and congestive heart failure (CHF) remain major causes of morbidity and mortality and impose a significant economic burden on most health systems (1). Initially, regeneration of cardiac muscle was thought to be the main mechanism involved in the improvement of cardiac function promoted by cell therapy (2). However, this capacity has been challenged, especially in the case of adult stem cells (3). Bone marrow (BM) mononuclear cells, BM-derived mesenchymal stem cells (MSCs), resident or endogenous cardiac stem cells, endothelial progenitor cells and induced pluripotent stem cells are some of the stem cell types that have been explored for their advantages and limitations in clinical 
use with significant heterogeneity in terms of efficacy. MSCs have been considered as the cells with the capacity for self-renewal, and differentiation towards the mesenchymal lineages. The second advantage with MSCs is lacking major histocompatibility complex II and B7 co-stimulatory molecule expression; hence, they are able to evade immune responses and have an innate ability to overcome the rejection. This opens the possibility of non-autologous transplantation in patients (4). After a decade of stem cell studies, there were still no consensus conclusions on BM mesenchymal cells use in heart muscle cell regeneration (5). BM has several limitations as a source of MSCs; being present at low frequency in $\mathrm{BM}$, the invasive procedures required for collection and the decline in their characteristics with donor's age. Adult stem cells have poorly characterized growth conditions and cannot be propagated quickly in vitro. Thus, they are not suitable for optimal transplantation time which has been confirmed in several clinical trials of four to seven days for acute myocardial infarction (6). Therefore, allogeneic transplantation methods need to be developed to address the issue of narrow transplantation time window in acute myocardial infarction. Among multiple sources of stem cells, human umbilical cord matrix, namely, Wharton's jelly (WJ), has recently become the preferential source of stem cells, because of rapid availability with a large donor pool, non-invasive collection, no risk for the donor, no ethical constraints, high in vitro expandable rates and multipotent differentiation potential which makes them important sources for the isolation and banking of stem cells (7-10). Due to proven immunomodulatory effects, WJ-derived MSCs (WJ MSCs) are now considered attractive agents for allogeneic cell therapy approaches. WJ-derived primitive stromal cells are a valuable alternative source of cells that possess multipotent properties between embryonic and adult stem cells $(11,12)$.

Catecholamines cause deleterious effect on the heart, associated with structural, functional and biochemical alterations. Isoproterenol (ISO) is a synthetic catecholamine and $\mathrm{B}$ - adrenergic agonist that causes necrosis of rat heart muscle and progressive global heart failure. ISO induced myocardial injury (MI) serves as a well standardized model to study the beneficial effects of many drugs and transplanted cells on cardiac functions $(13,14)$.

In the current study, we investigated the possibility of cardiac function improvement post ISO induced MI following WJ MSCs transplantation into Wistar rats. Study of heart rate, ECG and electrocardiographic patterns, cardiac marker enzyme changes, tracing of labeled MSCs and immunohistochemical analysis of myocardial cryosections were performed.

\section{Materials and Methods}

\section{Isolation of MSCs from Wharton's Jelly (WJ)}

Fragments of umbilical cords (4) were obtained from full term deliveries at the Obstetric Department Cairo University hospitals after informed consent and under complete aseptic conditions. All samples were tested for the absence of HIV, HBV and HCV and processed up to $4 \mathrm{hrs}$ from collection. Umbilical arteries, veins and the outer layer of the amniotic epithelium were removed then, the umbilical cords were dissected into small pieces which were mechanically minced in Petri dishes and seeded onto culture dishes precoated with $2 \mu \mathrm{g} / \mathrm{cm}$ fibronectin. Parts of minced tissue were digested by enzymatic mixture of $1 \mathrm{mg} / \mathrm{ml}$ collagenase type I (Sigma-Aldrich St. Louis, MO, USA) and $5 \mathrm{ml}$ Accutase (Sigma-Aldrich St. Louis, MO, USA) at $37^{\circ} \mathrm{C}$ for 60 minutes with permanent shaking, then filtered through a $100 \mu \mathrm{m}$ mesh filter (BD Bioscience USA). Cell suspensions were centrifuged at $400 \times \mathrm{g}$ for 10 minutes; cell pellets were washed with PBS and then cultured at a density of $1 \times 10^{5}$ cells $/ \mathrm{cm}^{2}$ in T25 culture flasks. Both Tissue explants and digested cell pellets were cultured in DMEM supplemented with $10 \%$ fetal bovine serum (FBS), antibiotics penicillin (100 units/ml) and Streptomycin (100 $\mu \mathrm{g} / \mathrm{ml})$ (Sigma-Aldrich St. Louis, MO, USA). Cultures were maintained at $37^{\circ} \mathrm{C}$ with $5 \% \mathrm{CO}_{2}$ and $21 \% \mathrm{O}_{2}$ in a humidified atmosphere. Medium was changed twice a week optimally. When cultures reached $80 \%$ to $90 \%$ confluence; MSCs, adherent to plastic dishes, were trypsinized using trypsin EDTA 0.25\% (Hyclone, Thermofisher Scientific), and replated for passaging. Cells obtained from passage 3 were used for characterization, labeling and animal injection.

\section{Characterization of WJ MSCs}

Morphology: A light inverted microscope (Olympus, Japan) equipped with a digital camera system for imaging (Olympus digital Net camera DN100), was used for morphology evaluation.

Immunophenotyping of cells using flow cytometry: Passage 3 cells were trypsinized, washed and resuspended in PBS at a concentrationof $1 \times 10^{6} / \mathrm{ml}$. The cells were stained for 20 minutes in the dark with monoclonal antibodies conjugated with fluorescein isothiocyanate (FITC) to CD13, CD29, CD90, CD73, CD45, CD14, CD146, and to phycoerythrin (PE) CD105, CD106, CD166, CD44, CD34, CD144, CD31, HLA DR. All monoclonal antibodies were purchased from Beckman coulter. 7-amino-actino- 
mycin D (7 AAD-Sigma Aldrich) was added for $20 \mathrm{mi}-$ nutes in all tubes to insure gating on viable cells. Mouse isotypic antibodies served as control. 10,000 cells were analyzed by CYTOMICS FC 500 Flow Cytometer (Beckman Coulter, FL, USA) using CXP Software version 2.2.

Multilineage differentiation assays: Osteogenic and adipogenic differentiation of WJ derived MSCs was tested using Human Mesenchymal Stem Cell Functional Identification Kit (R\&D, USA Catalog number SC006) according to manufacturer instructions. Adipocytes and osteocytes were detected by Oil red O stain, Alizarin red stain (Sigma-Aldrich St. Louis, MO, USA) respectively, 3 weeks later.

Proliferation studies: Colony-forming unit-fibroblast (CFU-F) assays were performed to evaluate MSCs clonal expansion capacity in DMEM complete media in triplicates. Briefly, single-cell suspensions at passagel were plated in six-well culture plate at densities of $1 \times 10^{3}$ per well. On day 14, the cell layer was fixed and stained. Individual colonies composed of at least 50 cells were counted.

\section{Labeling of WJ derived stem cells with PKH26 dye}

WJ MSCs were harvested during the $3^{\text {rd }}$ passage and were labeled with PKH26 fluorescent linker dye (Sigma Company, Saint Louis, Missouri, USA) according to manufacturer instructions. Cells were centrifuged and washed twice in serum free medium. Cells were pelleted and suspended in dye solution. MSCs were adjusted to $10^{6} / \mathrm{ml}$. After further centrifugation, cells were resuspended in PBS and kept on ice until infusion.

\section{Animal preparation}

Male adult Wistar rats, were obtained and housed at a controlled temperature $\left(23^{\circ} \mathrm{C}\right)$ with a $12: 12$ hour lightdark cycle, pathogen free housing and received standard Rat chow and water. All experiments were performed in conformity with the Guide for the Care and Use of Laboratory Animals (NIH) and were supervised by the animal facility of Cairo University. The study included 4 groups (total 60) of male Wistar rats weighing 220 250 gm.

Group 1: Normal control rats $(n=15)$.

Group 2: Rats injected with PKH-26 Fluorescent labeled MSCs $\left(5 \times 10^{6}\right.$ in $0.5 \mathrm{ml}$ saline), IV in tail vein $(n=15)$.

Group 3: ISO model; rats were injected subcutaneously with 2 doses of isoproterenol $85 \mathrm{mg}$ and $150 \mathrm{mg} / \mathrm{kg}$ body weight on 2 consecutive days $(n=15)$.

Group 4: Rats injected with ISO (same doses) then injected IV (tail vein) with PKH-26 labeled MSCs $\left(5 \times 10^{6}\right.$ in $0.5 \mathrm{ml}$ saline), on third day $(\mathrm{n}=15)$.

Tracing Fluorescently labeled MSCs in rat tissues: Labelled WJ MSCs were injected IV in tail vein of groups $2 \sim 4$. After 7 days, 7 rats from all groups were sacrificed. Hearts were dissected out, immediately washed in ice cold saline. Hearts were frozen immediately then sliced into 3 5 $\mu \mathrm{m}$ thick sections. Tissues (lungs, kidneys and spleen) were cryopreserved, then sliced, fixed and stained with hematoxylin and eosin (HE). Groups 2 and 4 frozen tissue sections were examined with fluorescence microscope (Leica, Germany) to detect and trace the cells stained with red PKH26.

\section{Biochemical assays for cardiac enzymes}

Cardiac enzyme levels were analyzed using samples taken from rat tail veins (group 1, 2, 3, 4) on day 5 after injury. Serum was obtained from rat blood samples. Quantitative measurement of creatine kinase $\mathrm{MB}$ isoenzymes, CK mass and Troponin (cTnT), CK total, LDH as well as AST were performed. Kinetic determination of enzyme activity assays was performed using specific kits and a spectrophotometer.

Electrocardiography (ECG): Needle subcutaneous peripheral limb electrodes were inserted $12 \mathrm{~h}$ after the second dose of isoproterenol and an electrocardiogram (ECG) was continuously recorded (HPM 7100, Fukuda Denshi, Tokyo, Japan) to determine QRS amplitude and duration. Animals were kept warm during the operation with a heating lamp to prevent the incidence of hypothermia. Heart rate and type of alterations (ST-segment elevation or depression) in normal and experimental animals were recorded.

Ecchocardiography: Spontaneously breathing rats were screened by echocardiography using an Accuson Cypress echo-machine (Siemens, Germany) using an $8 \mathrm{MHz}$ probe to measure left ventricle (LV) dimensions in the long-axis parasternal view by $\mathrm{M}$-mode. Left ventricular end diastolic diameter (LEDD) and left ventricular end systolic diameter (LESD) were measured. Fractional shortening (FS) and ejection fraction (EF) were automatically calculated by the machine using the Teich method. These measurements were averaged over three cardiac cycles.

\section{Immunohistochemical analysis for myosin, troponin and actin}

Six rats from groups 2, 4 and controls were sacrificed 6 weeks later. Heart tissues were tested by immune histochemistry for the presence of incorporated human WJ stem cells. Heart tissue cryosections were fixed with paraformaldehyde $4 \%$ at room temperature for 10 minutes, blocked with peroxide then serum blocking reagents, 
rinsed then blocked with avidin followed by biotin blocking reagents. Cells were then stained overnight at $4^{\circ} \mathrm{C}$ with primary antibodies against human myocardium specific $\alpha$ smooth muscle actin (R\&D USA \#MAB1420), human myosin heavy chain (R\&D USA \#MAB 4470) and antihuman troponin T (R\&D USA \#MAB1874). Incubation with biotinylated 2ry antibodies followed using antimouse HRP-DAB system cell \& tissue staining kit (R\&D, USA \# CTS002) according to manufacturer's instructions. Cells with granular brown DAB reaction in the cytoplasm were considered positive for the examined protein. Calculation of ratio of positive cells in ten visual fields $(\times 200)$ under microscope was performed.

\section{Statistical analysis}

All statistical calculations were done using computer programs SPSS (Statistical Package for the Social Science; SPSS Inc., Chicago, IL, USA) version 20 for Microsoft Windows. Data were statistically described in terms of mean \pm standard deviation $( \pm S D)$, frequencies when appropriate. Paired t test were used for comparison of numerical variables between the study groups. p values less than 0.05 were considered statistically significant.

\section{Results}

\section{Characterization of WJ MSCs}

Adherent cells with a fusiform- like phenotype started to grow in tissue culture flasks and from explants in
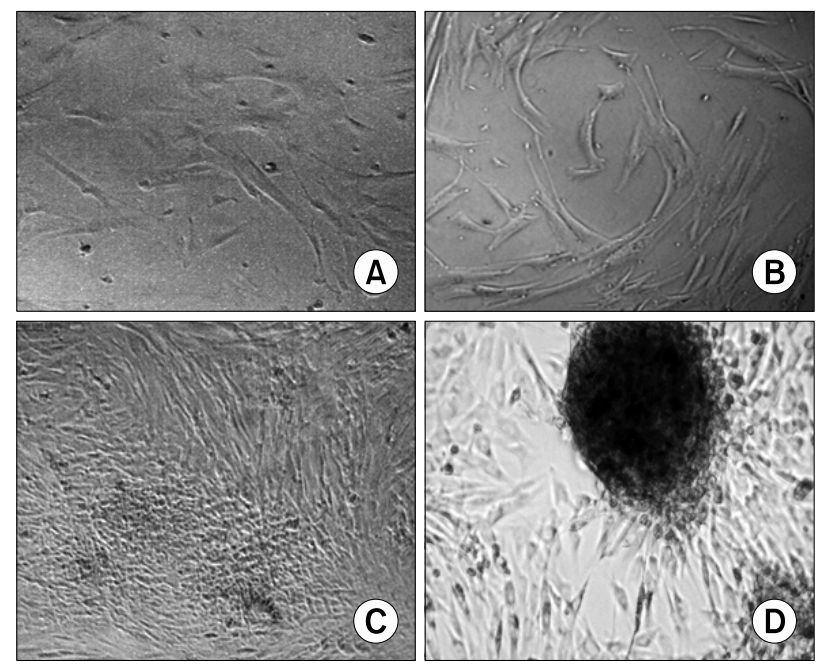

Fig. 1. (A, B) Morphology; Representative phase-contrast images of WJ MSCs on day 7 primary cultures. In both cultures, cells appear elongated and spindled-shaped (10 $\times$ and $20 \times$ magnification). (C) Confluent growth $10 \times$ magnification. (D) WJ explant with cell outgrowths. dishes after approximately 10 to 12 days from the initial culture. Cells were first passaged after 15 days of culture. After passage 3, WJ MSCs became homogeneous and showed a fibroblast-like (elongated spindle) morphology (Fig. 1). WJ derived MSCs posses a high proliferation potential, they were expanded for more than 14 passages while maintaining their undifferentiated state. Afterwards cell growth slows, vacuoles appear in cell cytoplasm with eventual cell death.

In vitro differentiation showed that isolated WJ MSCs under specific culture conditions presented moderate osteogenic and low adipogenic differentiation (Fig. 2A). Fatty vacuole deposits of WJ MSCs after 21 days of differentiation were visualized by Oil Red O staining (Fig. 2B).

Immunophenotyping of the cells in the 3rd passage revealed characteristics of MSCs surface marker profile (Fig. 3 ). As the cells were positive for endoglin receptor CD105, the surface enzyme ecto-59-nucleotidase CD73, the extracellular matrix protein CD90, the activated leukocyte cell adhesion molecule CD166, the $\beta 1$-integrin CD29, hyaluronate receptor CD44, 106 as well as146 (Endothelial marker), at high levels (>85\%), mild increase in endothelial cell marker CD31 and negative for hematopoietic and monocytic cell markers (CD34, CD45, CD14), HLA-DR and CD 144 (very low levels).

\section{Tracing of Fluorescent labeled MSCs in myocardial tissue}

Animals (groups 2\&4) were sacrificed (7 days later) and

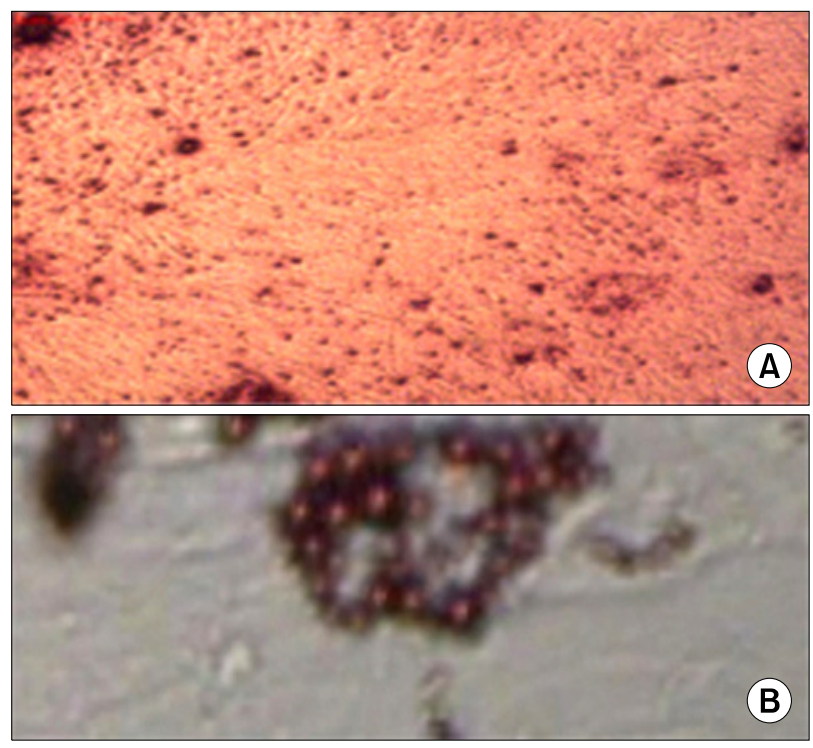

Fig. 2. (A) Osteogenic differentiation of MSCs (Alizarin red stain) $20 \sim 25$ days culture. (B) Adipogenic differentiation of MSCs (OIL Red O stain) 18 21 days culture. 

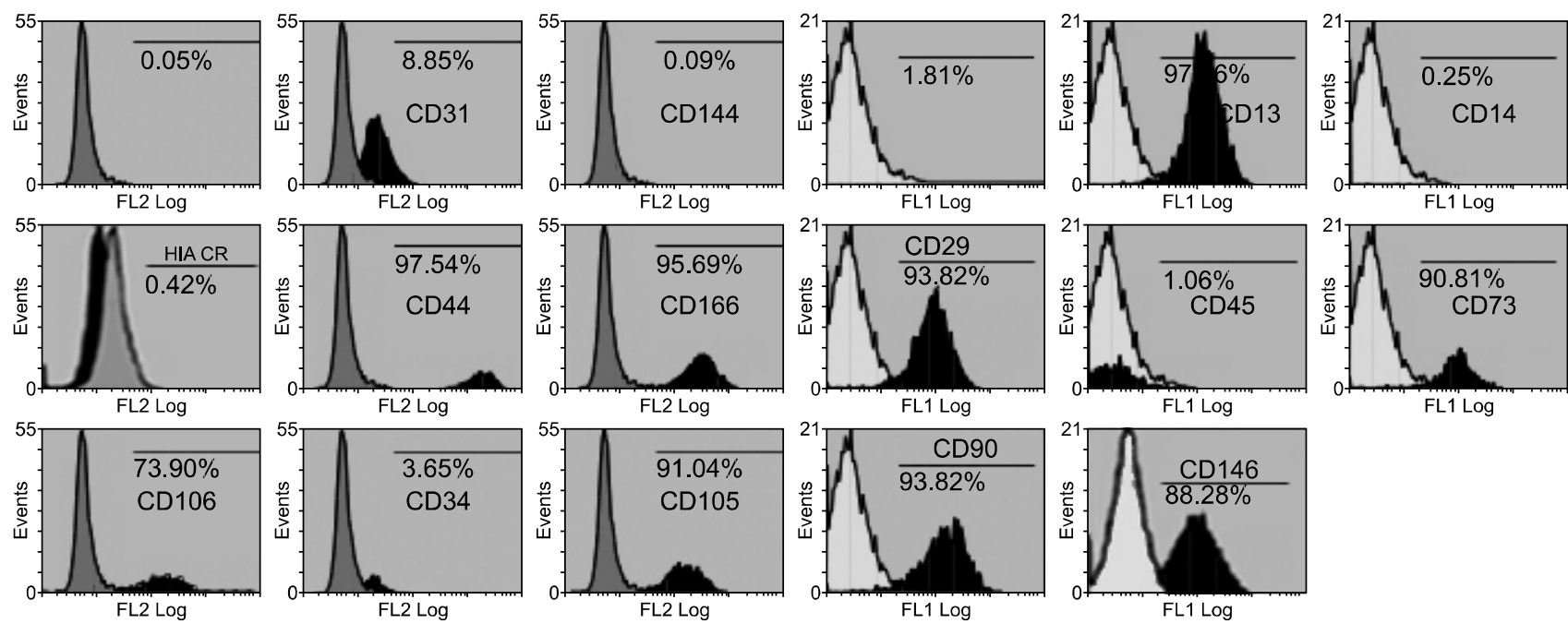

FL1 Log

Fig. 3. Representative flow cytometric plots, including isotype control (IgG1-PE and IgG1-FITC) Flowcytometry charts of WJMSCs demonstrate abundance of cells positive for CD105, CD90, CD73, CD106, CD44, CD29 CD166, CD13, CD146 expressed as percentages. Negative for CD144, CD34, CD45, CD14 and HLA DR. Mild increase in CD31. MSCs were consistently positive for MSCs markers, negative for hematopoetic, monocytic and HLA DR markers.

cardiac tissue, kidneys, spleen and lungs were harvested, cryosections and HE stained sections were studied. PKH26 cell membrane linker dye was detected in vitro after cell labeling (before transplantation) by fluorescent microscope at excitation $(551 \mathrm{~nm})$ and emission $(567 \mathrm{~nm})$. Fluorescein labeled MSCs were detected only in cardiac tissue of ISO injected rats (group 4) (Fig. 4).

MSCs were not seen in group 2, they were not seen also in kidneys, spleen and minimally in lungs in both injected groups 2 and 4 (Fig. 5).

\section{Biochemical markers}

Cardiac markers were positively altered in group 4 compared to group 3, with levels approaching control group 1 (Table 1). The serum CK mass, CK Total, LDH and Troponin (cTnT) concentrations in ISO group3 showed a significant increase in the activities of these enzymes in serum compared to controls $(\mathrm{p}<0.001$ high statistical significance for all). Treatment with MSCs in ISO rat (group 4) significantly reduced the activities of such enzymes compared to ISO rats (group 3) $(\mathrm{p}<0.001$ high statistical significance for all except for LDH $\mathrm{p}>0.05$ ) with levels approaching the normal control group 1 ( $p>0.05$ of no statistical significance) (Table 1).

\section{ECG and echocardiography}

Rats that received isoproterenol (dosage of $150 \mathrm{mg} / \mathrm{kg}$ ) showed cardiac enlargement and disseminated ventricular ischemic lesions, which resulted in death rates of $60 \%$ in group 3 by day 5 . ECG groups $1 \& 2$ (Normal rats) showed a Heart Rate ranging from $270 \sim 300 / \mathrm{min}$; PR interval 40 50 msec. and QRS duration 50 60 msec. whereas ISO rats (group 3) had a Heart Rate range of 350 360/min; PR interval 30 40 msec; QRS duration 70 80 msec. with RSR' pattern denoting intraventricular conduction delay (bundle branch block).

ISO and MSCs injected rats (group 4) had a Rate of 280/min, PR interval 40 50 msec and QRS duration 40 msec. ECG changes showed improvement after MSCs injection with normalization of heart rate (Fig. 6). Elevation of ST segment, which indicate ischemia in the apex and in the lateral left ventricular wall, was found in $65 \%$ of group 3 rats.

\section{Echocardiography}

Table 2 shows means \pm SD of Echocardiography parameters in the studied groups. A significant difference between groups 1,2 \& group $3(\mathrm{p}<0.05)$ was found regarding $\mathrm{EF} \%$, LESV $(\mu 1)$, LEDV ( $\mu \mathrm{l})$ with no difference between groups $1 \& 2$.

However regarding FS \%, there was no significant difference between all groups.

$\mathrm{EF} \%$ and LESV ( $\mu \mathrm{l})$ and LEDV were significantly improved in ISO-MSCs (group 4) when compared to group3, $\mathrm{p}<0.05$. Cell therapy had a significant effect when comparing cell-treated (group 4) and ISO (group 3). Septal motion defect was observed in $70 \%$ of ISO rats group 3 (Fig. 7). 


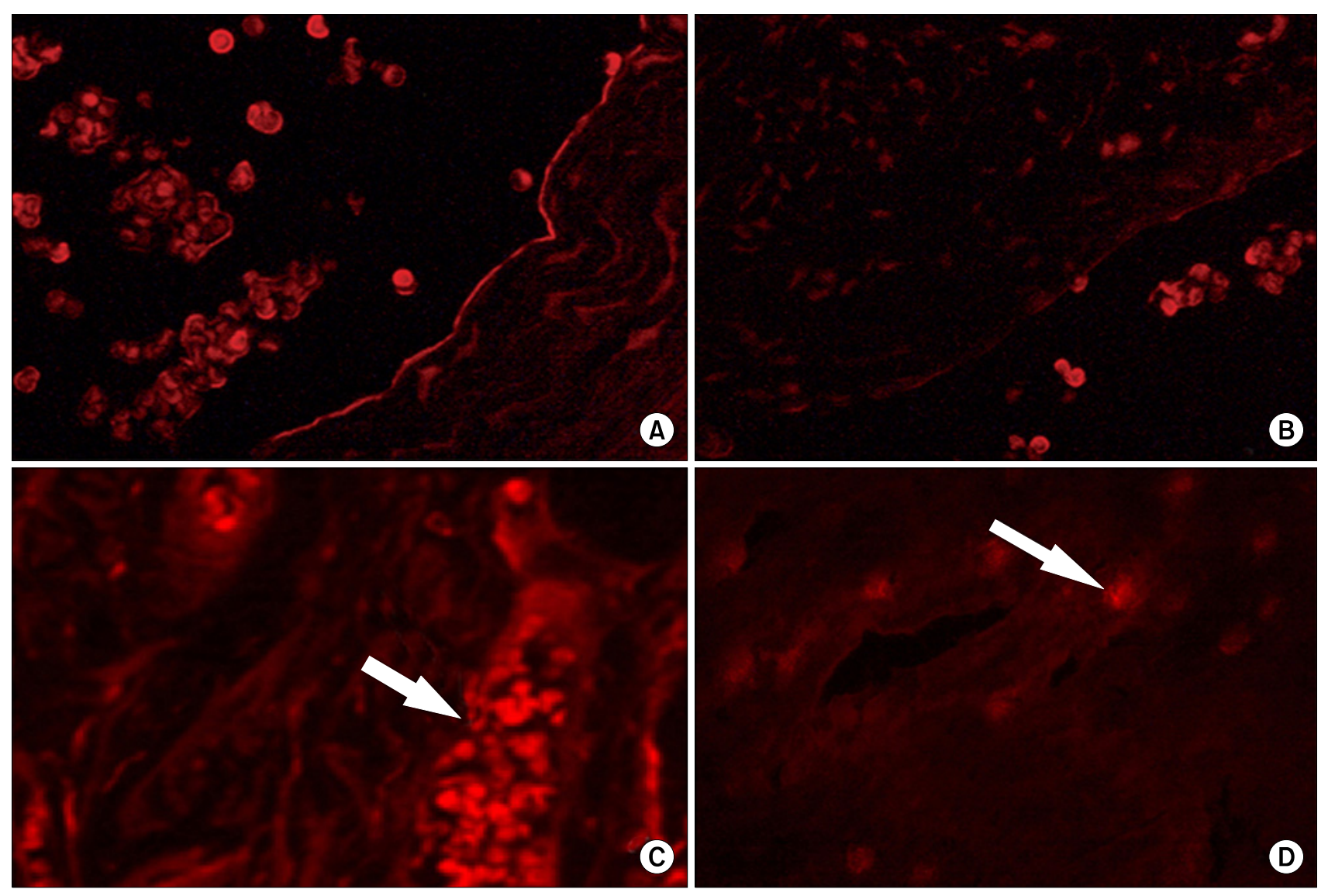

Fig. 4. (A) Myocardial Cryosections of ISO rats transplanted (group 4) with PKH2 labeled WJMSCs showing strong red fluorescence invading myocardial tissue $(40 \times$ magnification). (B, C) Homing of PKH2 labelled MSCs in heart tissue of group 4 (40× magnification). (D) WJ MSCs were incorporated in the whole ischaemic cardiac tissue group 4 (100× magnification).
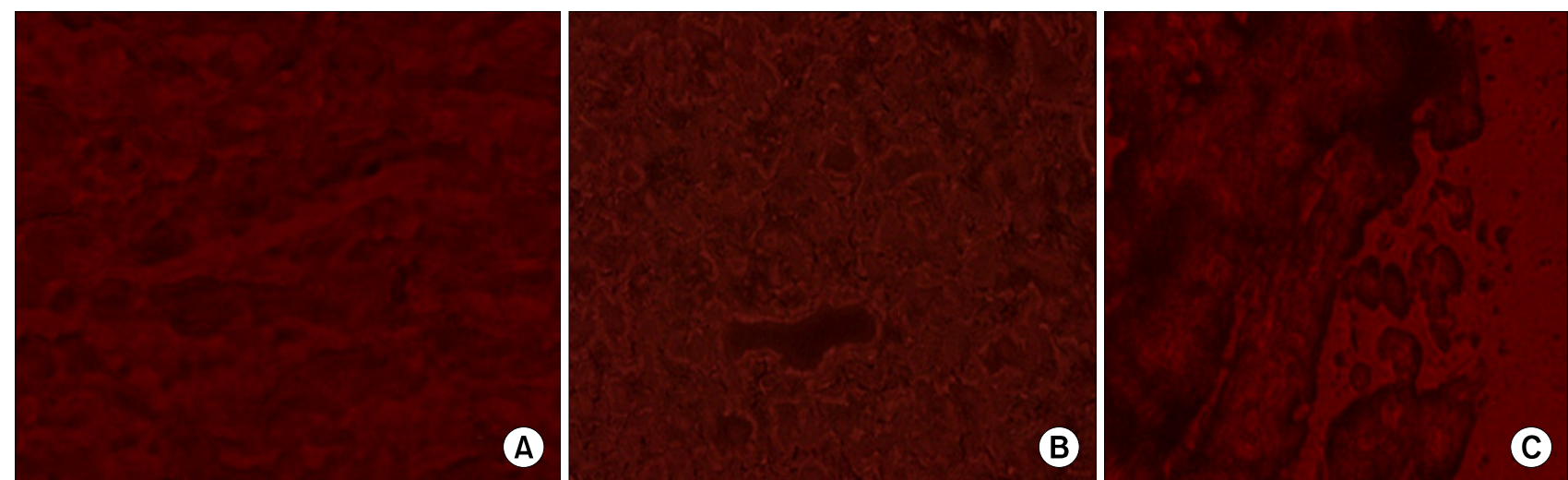

Fig. 5. (A) Myocardial cryosections of group1 (negative control group). (B) Myocardial cryosections of group 2 (normal rats injected with PKH2 labelled WJ MSCs), showing absence of labeled MSCs denoting their loss in the circulation. (C) Lung cryosection from ISO rats injected with labeled WJ MSCs (group 4). Absence of red fluorescence in lung tissue and their presence in cardiac sections denotes homing of cells only in damaged tissues, animals sacrificed at day 7 .

\section{Survival rate}

Group 1 and 2 had survival of 14/15 (93.3\%) rats after 6 weeks; group 3 had survival of 4/15 (26.6\%) after 3 weeks and $1 / 15(6.6 \%)$ at 6 weeks; group 4 had survival of $12 / 15(80 \%)$ after 6 weeks. Thus the survival rate is much higher in group 4 compared to group 3 . 
Table 1. Biochemical markers in the studied groups

\begin{tabular}{lcccc}
\hline Parameter & Group (1) & Group (2) & Group (3) & Group (4) \\
& Mean \pm S.D & Mean \pm S.D & Mean \pm S.D & $0.057 \pm 0009^{*}$ \\
CK mass ng/ml & $0.03 \pm 0.01$ & $0.03 \pm 0.01$ & $0.76 \pm 0.117$ & $559.9 \pm 335.5^{*}$ \\
CK total U/L & $161.8 \pm 95.3$ & $180.4 \pm 88$ & $834.3 \pm 251.2$ & $652.3 \pm 231.2$ \\
LDH U/L & $212.9 \pm 134.2$ & $203.7 \pm 152$ & $795.4 \pm 281.4$ & $123.4 \pm 29.57^{*}$ \\
GOT U/L & $96.3 \pm 21.98$ & $110.6 \pm 30.6$ & $234.4 \pm 33.5$ & $0.019 \pm 0.007^{*}$ \\
Ctnl ng/ml & $0.016 \pm 0.001$ & $0.014 \pm 0.005$ & $0.071 \pm 0.005$ & 0.005 \\
\hline
\end{tabular}

*Group 4 showed reduced cardiac enzymes compared to group 3 for all parameters except for $\mathrm{LDH}(\mathrm{p}<0.001$ statistical significance), with levels approaching control group 1.

Table 2. Echocardiography parameters $($ Mean \pm SD)

\begin{tabular}{lllll}
\hline Parameter & Group (1) & Group (2) & Group (3) & Group (4) \\
\hline E.F \% & $59.8 \pm 2.4$ & $51.2 \pm 2.7$ & $26.4 \pm 3.0$ & $34.3 \pm 3.1$ \\
LESV $(\mu \mathrm{l})$ & $31.6 \pm 2.7$ & $35.6 \pm 7.0$ & $62.4 \pm 7.3$ & $55.5 \pm 6.2$ \\
LEDV $(\mu \mathrm{l})$ & $62.6 \pm 4.2$ & $63.8 \pm 3.4$ & $90.5 \pm 7.3$ & $81.2 \pm 5.6$ \\
FS \% & $43.2 \pm 3.8$ & $44.3 \pm 4.1$ & $43.3 \pm 3.4$ & $46.3 \pm 4.8$ \\
\hline
\end{tabular}

A significant difference between groups 1,2 \& group $3(p<0.05)$ was found regarding EF\%, LESV $(\mu \mathrm{l})$, LEDV $(\mu \mathrm{l})$ with no difference between groups $1 \& 2$. They were significantly improved in ISO-MSCs (group 4) when compared to group3 $(\mathrm{p}<0.05)$.

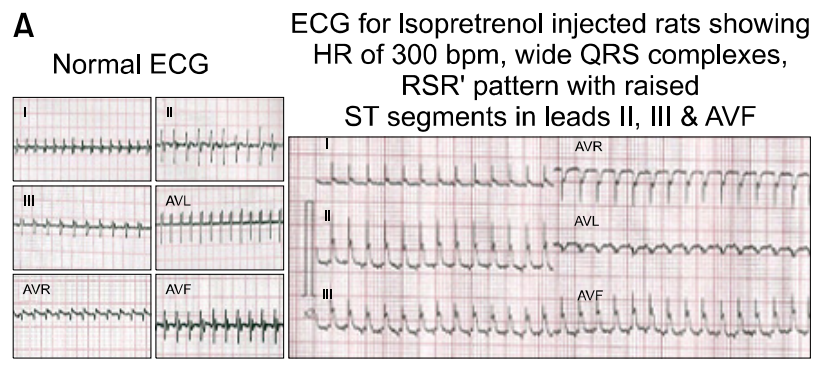

\section{B}

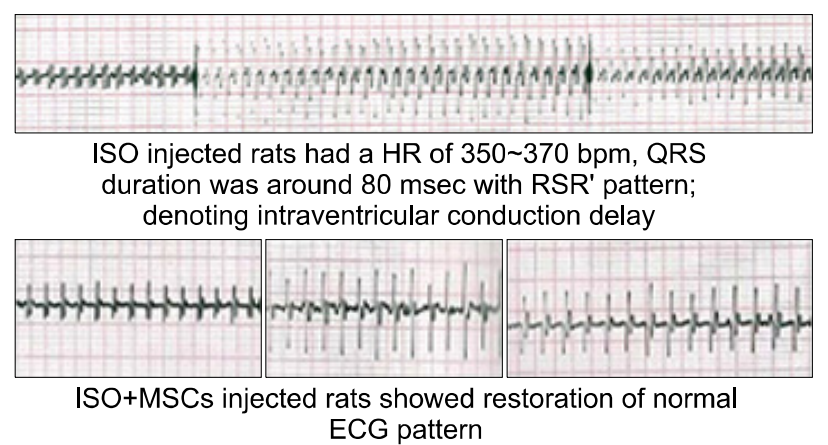

Fig. 6. ECG groups $1 \& 2$ (Normal rats) showed a Heart Rate ranging from 270 300/min; PR interval 40 50 msec. and QRS duration $50 \sim 60$ msec. whereas ISO rats had a Heart Rate range of 350 360/min; PR interval 30 40 msec; QRS duration 70 80 msec. with RSR' pattern' denoting intraventricular conduction delay (bundle branch block). ISO and WJMSCs injected Rats (group 4) had a Rate of 300/min, PR interval 40 50 msec and QRS duration 40 msec. with normalization of heart rate.

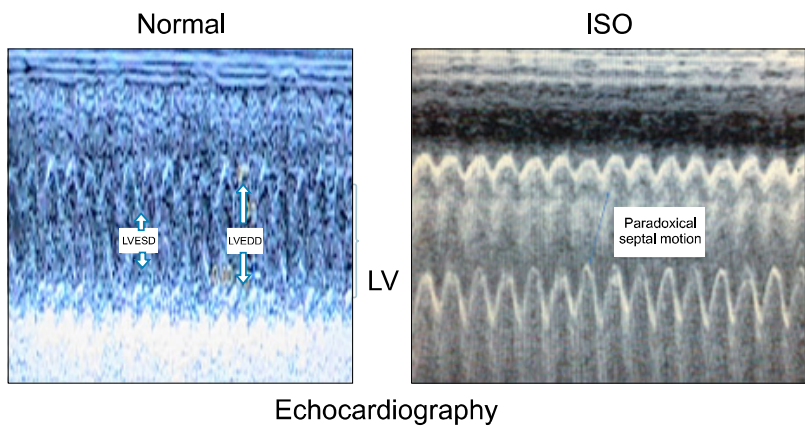

Fig. 7. Echocardiography: ISO injected rats showing Paradoxical septal motion.

\section{Immunohistochemistry}

Troponin T, $\alpha$-Smooth Muscle Actin and Myosin heavy chain were detected in cryosections of rat heart (group 4) demonstrating human MSCs engraftment and differentiation into cardiac like cells using corresponding Mouse Anti-Human monoclonal antibodies. Human engrafted MSCs were stained brown denoting secretion of specific proteins. Specific brown staining was localized to cell cytoplasm (Fig. 8 and 9). Group 2 cryosections were negative for MSCs engraftment and showed completely normal myocardial sections.

\section{Discussion}

In this study, we reported that under appropriate culture conditions, cells having MSCs characteristics could be isolated from the matrix of the human umbilical cord; furthermore, the ability of these cells to integrate into ischaemic cardiac tissue was validated in vivo. Systemically, infused MSCs in the rat model of myocardial infarction were selectively recruited to the injured area. This recruitment was associated with cardioprotection, improved cardiac functions and increased survival.

WJ MSCs in the present study exhibited a mesenchymal like morphology, showing a robust MSCs profile through 

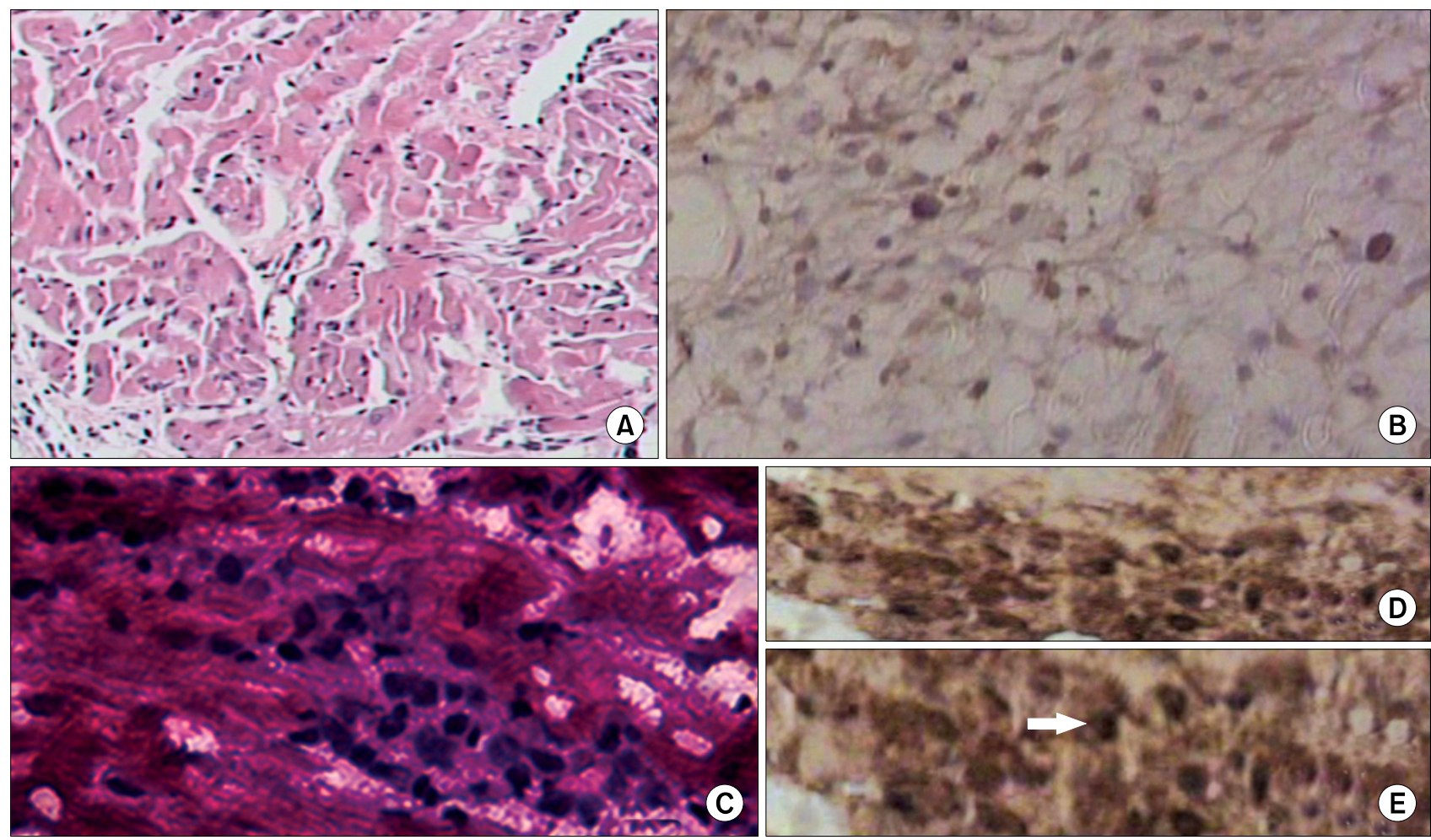

Fig. 8. (A) Shows control group myocardial cryosections stained with $(\mathrm{H} \& \mathrm{E}, 40 \times)$. (B) Shows control group unstained myocardial cryosections (200× magnification). (C) Group 4 cardiac tissue section showing homing of MSCs. They formed grape shaped cell clusters (H\&E, 200×). (D) Group 4 cardiac tissue section showing same cell cluster with cytoplasm staining brown with anti myosin monoclonal antibody (IHC, DAB $\times 200$ ). (E) The same cell cluster with a higher magnification $(400 \times)$. Cells' morphology was changed from spindle to round shape.

expression of CD44, CD90, CD73, CD105 surface markers and being negative for hematopoietic markers CD34 and CD45. They have a multipotent differentiation potential into adipogenic and osteogenic cell lineages

In the present study, administration of WJ derived MSCs showed a protective effect against ISO- alterations in various cardiac, biochemical and histopathological parameters. Stem cells caused restoration of heart rate and ECG values to normal, amelioration of ejection fraction and a significant decrease in the levels of LDH, CK and troponin. A number of articles in different disease models showed that xenotransplantation of MSCs had a therapeutic effect (15) due to immunomodulatory properties. Though, in principle, transplantation of a xenogenic graft might induce a local immune response in the host, preclinical and clinical reports have raised the possibility of using Human umbilical cord derived cells without immunosuppression (16). Therefore, to assess the safety and unbiased efficacy of these cells, immunosuppression was omitted in this study. Stem cells can be chemotactically attracted to the site of injury. It is thus reasonable to opt for systemic rather than intracardiac delivery to avoid tis- sue damage at the injection site (17). In vivo, strong evidence in favor of MSCs multipotency is derived from a study testing the fate of hMSCs after systemic administration into fetal sheep early in gestation (18). In this xeno-genic system, human MSCs engrafted and persisted in multiple tissues for long time after transplantation.

The present results revealed that intravenously implanted WJ MSCs could migrate into the damaged heart of hosts, and especially migrate directionally and survive in the cardiac tissue, with minimal presence in other tissues. Several studies have tested MSCs transplantation in experimental myocardial injury models. Overall, the results show that the milieu surrounding the infarcted tissue seems to attract the MSCs and promote their engraftment. Indeed, when injected systemically, MSCs preferentially home to the infarcted area and to the border zone, while their number in the remote areas is limited. Although the underlying mechanisms remain unclear, ischemic tissue may express specific receptors or ligands to facilitate trafficking, adhesion, and infiltration of MSCs to ischemic sites (19). Present data also demonstrated that, after few weeks, MSCs integrate and differentiate into cells express- 

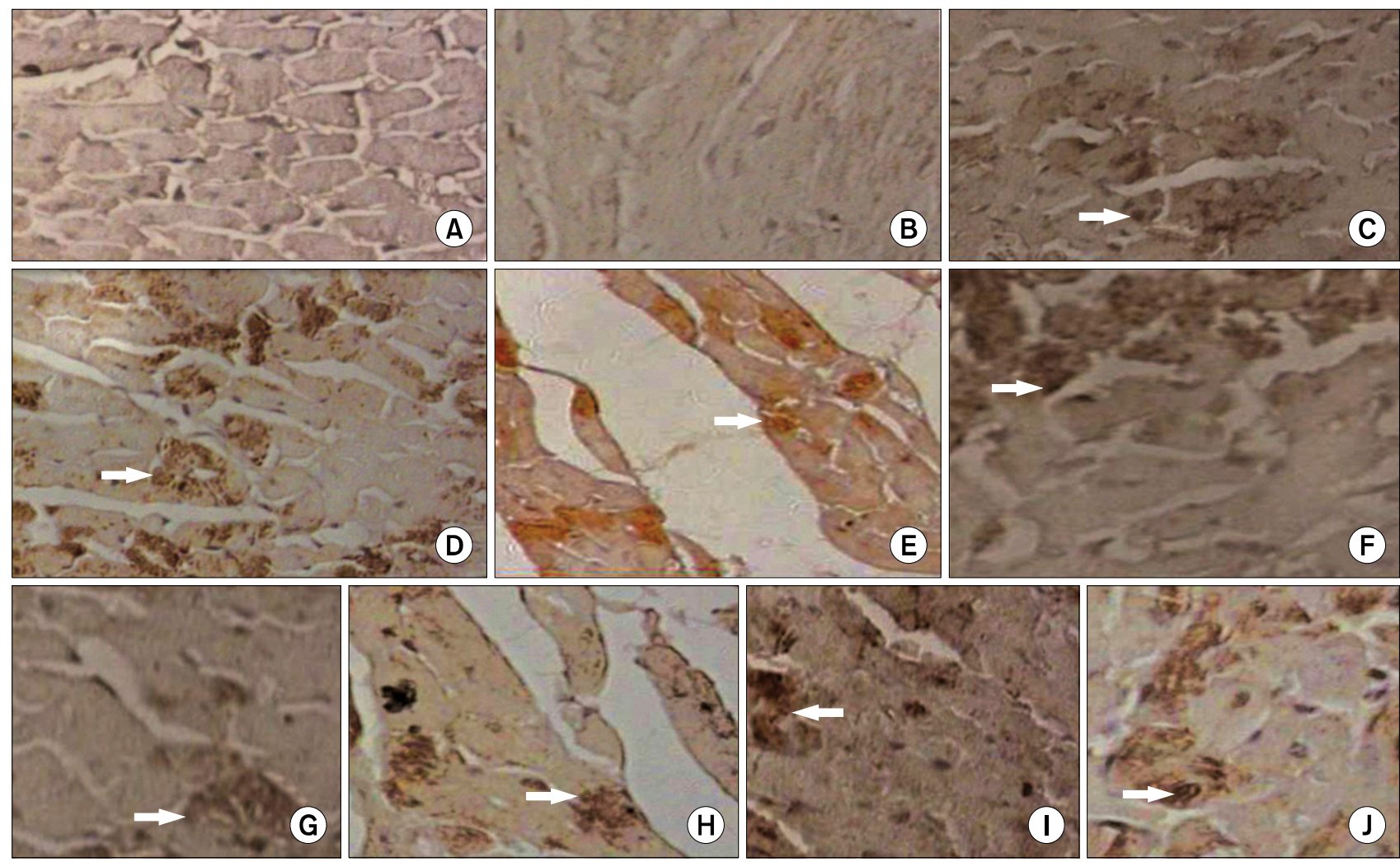

Fig. 9. Immunostaining for ISO rats group 4 transplanted with h WJMSCs, showing cells positive for specific cardiac proteins as brownish intracytoplasmic stain $(\mathrm{IHC}, \mathrm{DAB}$, troponin, 200 $\mathrm{x}$ ). (A) Control group 1 showing non staining of cardiac tissue cross sections with anti human troponin monoclonal antibody $(I \mathrm{HC}, \mathrm{DAB}, \times 200)$. (B) Group 4 shows longitudinal cardiac sections lacking staining if primary antibodies are omitted and tissue is stained only with secondary antibody followed by incubation with detection reagents (reaction negative control. (C) $\alpha$-Smooth Muscle Actin was detected in cryosections of mouse heart using Mouse. Anti-Human $\alpha$-Smooth Muscle Actin Monoclonal Antibody followed by the anti-Mouse HRP- DAB. Human embedded MSCs were stained brown denoting differentiation and secretion of $\alpha$-Smooth Muscle Actin protein. Only integrated Human WJ MSCS showed the stain, rest of the tissue was negative (IHC, DAB, actin $200 \times$ ). (G) and (J) show as well smooth muscle actin but with a higher magnification $\times 400$. (D, E, H) Troponin T was detected in cryosections of rat heart tissue demonstrating human MSCs differentiated into cardiac- like cells positive for troponin using Mouse AntiHuman Troponin (Cardiac) Monoclonal Antibody. Specific brown staining is localized to cell cytoplasm, as granular deposits (IHC,DAB, troponin 200 $\times$ ). (F) Myosin heavy chain was detected in mouse heart tissue with many cells positive for myosin as brownish intracytoplasmic stain $(\mathrm{IHC}, \mathrm{DAB}$, myosin $\times 400)$. (I) $(\mathrm{IHC}, \mathrm{DAB}$, myosin $200 \times)$.

ing a variety of cardiac-specific markers [actin, myosin and troponin] as tested by immunohistochemistry. Same results were obtained by Amado et al. (20). These cardiac-like cells seem also to be functionally connected with the native cardiomyocytes (CMC). Numerous in vivo rodent and swine studies have demonstrated the ability of MSCs to engraft and differentiate within the heart (4-6). In a rat model, both allogeneic and syngeneic MSCs improved EF 3 months after MI; however, allogeneic cells were eliminated from the heart by 5 weeks and functional benefit was lost within 5 months $(21,22)$. In the present study results showed xenogeneic cells were not eliminated by 6 weeks but unfortunately prolonged engraftment was not studied.
Engraftment has become a critical issue for cell-based therapies as many groups have demonstrated that the majority of the injected cells are lost after very few days (23). However, the fact is that, either on a syngeneic, allogeneic or xenogeneic setting, permanent engraftment of transplanted cells does not occur (22). Hereby this study postulate that regeneration due to transdifferentiation of WJ MSCs, may not be the primary mechanism involved in the improvement of cardiac function, favoring the "paracrine hypothesis". There is a growing body of evidence supporting the hypothesis that paracrine mechanisms mediated by factors released by MSCs play an essential role in the reparative processes observed after stem cell injection into infarcted hearts $(24,25)$. Cytokines and growth factors im- 
prove angiogenic, anti- inflammatory activities, and anti-apoptotic effects; hence favor neovascularization, cytoprotection and endogenous cardiac regeneration. Furthermore, post-infarction inflammatory and fibrogenic processes, cardiac contractility and cardiac metabolism may also be influenced in a paracrine fashion $(24,25)$. Apart from cytokine/chemokine secretion, MSCs also display a strong capacity for mitochondrial transfer and microvesicle (exosomes) secretion in response to injury with subsequent promotion of tissue regeneration (26). These unique properties of MSCs make them an invaluable cell type to repair damaged tissues/organs. Intravenous allogeneic MSCs infusion proved to be safe in a phase-I trial in patients with acute MI, improved left ventricular function, induced reverse remodeling, and decreased scar size (27-29). Endoventricular allogeneic MSCs injection has been associated with reduced adverse cardiac events in a phase-II trials in patients with chronic heart failure (30, 31). Classically, it is believed that an ideal stem cell should differentiate into cardiomyocytes that integrate both mechanically and electrically with innate myocytes and should be able to form blood vessels to boost the blood supply to the scar zone. On the other hand, recent studies suggest that paracrine factors secreted by the stem cells may play a more important role in the improvement of cardiac function (25). This has changed the belief that the stem cells must differentiate into cardiac cell types to improve cardiac function. Hence, stem cell types which are not multi-potent themselves can still improve cardiac function comparably to stem cells committed to cardiac lineages. The next step now is to systematically characterize these cells by their ability to differentiate into cardiac cell types and their ability to improve cardiac health by paracrine mechanisms (32).

WJ MSCs are unique. They are not susceptible to spontaneous malignant transformation, even though they have a number of embryonic cell markers, induced pluripotent stem cells have the potential of tumorigenesis (33). Thus in contrast to other allogenic mesenchymal cell types (34), WJMSCs do not elicit an allogenic immune response of transplant rejection (35).

\section{Conclusions}

Results of the present study, demonstrated that intravenously administered WJ derived MSCs were recruited predominantly in the ischemic myocardium whereas few MSCs were detected in other normal tissues (lungs, kidneys and spleen). This recruitment was associated with cardioprotection, improved cardiac functions and in- creased survival. Cardiac markers were positively altered in group 4 (WJ MSCs transplanted group) compared to group 3, with levels approaching control group. ECG changes showed dramatic improvement after MSCs injection. MSCs could differentiate into cardiac-like cells in vivo. Thus systematically administered WJ MSCs promote rapid cardiac repair and reduce mortality. The results of this study indicate that MSCs infusion is a promising therapeutic strategy for myocardial insufficiency. WJ MSCs could be obtained easily with no ethical constraints, however their differentiaton into osteogenic and adipogenic lineages was lower.

\section{Acknowledgments}

This work has been sponsored by RAMSES an FP7REGPOT- project (No. 245691). Authors are greatly indebted to Prof Dr Konrad Brockmeier, Professor of Pediatrics, University of Cologne, Faculty of Medicine, Director of Pediatric Cardiology Heart Centre Cologne and the Coordinator of RAMSES FP7project, for his great help and kind support all over. We would like to thank Dr Rabab El Hawary, lecturer of immunology Cairo University for helping in cultures and the flow cytometric studies.

\section{Potential conflict of interest}

The authors have no conflicting financial interest.

\section{References}

1. Butler D. UN targets top killers. Nature 2011;477:260-261

2. Rota M, Kajstura J, Hosoda T, Bearzi C, Vitale S, Esposito G, Iaffaldano G, Padin-Iruegas ME, Gonzalez A, Rizzi R, Small N, Muraski J, Alvarez R, Chen X, Urbanek K, Bolli R, Houser SR, Leri A, Sussman MA, Anversa P. Bone marrow cells adopt the cardiomyogenic fate in vivo. Proc Natl Acad Sci U S A 2007;104:17783-17788

3. Wagers AJ, Sherwood RI, Christensen JL, Weissman IL. Little evidence for developmental plasticity of adult hematopoietic stem cells. Science 2002;297:2256-2259

4. Kuraitis D, Ruel M, Suuronen EJ. Mesenchymal stem cells for cardiovascular regeneration. Cardiovasc Drugs Ther 2011;25:349-362

5. Gnecchi M, Danieli P, Cervio E. Mesenchymal stem cell therapy for heart disease. Vascul Pharmacol 2012;57:48-55

6. Vassalli G, Moccetti T. Cardiac repair with allogeneic mesenchymal stem cells after myocardial infarction. Swiss Med Wkly 2011;141:w13209

7. Bongso A, Fong CY. The therapeutic potential, challenges and future clinical directions of stem cells from the Wharton's jelly of the human umbilical cord. Stem Cell Rev 2013;9:226-240 
8. La Rocca G, Lo Iacono M, Corsello T, Corrao S, Farina F, Anzalone R. Human Wharton's jelly mesenchymal stem cells maintain the expression of key immunomodulatory molecules when subjected to osteogenic, adipogenic and chondrogenic differentiation in vitro: new perspectives for cellular therapy. Curr Stem Cell Res Ther 2013;8:100-113

9. Fong CY, Chak LL, Biswas A, Tan JH, Gauthaman K, Chan WK, Bongso A. Human Wharton's jelly stem cells have unique transcriptome profiles compared to human embryonic stem cells and other mesenchymal stem cells. Stem Cell Rev 2011;7:1-16

10. Batsali AK, Kastrinaki MC, Papadaki HA, Pontikoglou C. Mesenchymal stem cells derived from Wharton's Jelly of the umbilical cord: biological properties and emerging clinical applications. Curr Stem Cell Res Ther 2013;8:144-155

11. Troyer DL, Weiss ML. Wharton's jelly-derived cells are a primitive stromal cell population. Stem Cells 2008;26:591599

12. Nekanti U, Rao VB, Bahirvani AG, Jan M, Totey S, Ta M. Long-term expansion and pluripotent marker array analysis of Wharton's jelly-derived mesenchymal stem cells. Stem Cells Dev 2010;19:117-130

13. Yates JC, Dhalla NS. Induction of necrosis and failure in the isolated perfused rat heart with oxidized isoproterenol. J Mol Cell Cardiol 1975;7:807-816

14. Knufman NM, van der Laarse A, Vliegen HW, Brinkman CJ. Quantification of myocardial necrosis and cardiac hypertrophy in isoproterenol-treated rats. Res Commun Chem Pathol Pharmacol 1987;57:15-32

15. Li J, Ezzelarab MB, Cooper DK. Do mesenchymal stem cells function across species barriers? Relevance for xenotransplantation. Xenotransplantation 2012;19:273-285

16. Yang WZ, Zhang Y, Wu F, Min WP, Minev B, Zhang M, Luo XL, Ramos F, Ichim TE, Riordan NH, Hu X. Safety evaluation of allogeneic umbilical cord blood mononuclear cell therapy for degenerative conditions. J Transl Med 2010; $8: 75$

17. Willing AE, Lixian J, Milliken M, Poulos S, Zigova T, Song S, Hart C, Sanchez-Ramos J, Sanberg PR. Intravenous versus intrastriatal cord blood administration in a rodent model of stroke. J Neurosci Res 2003;73:296-307

18. Liechty KW, MacKenzie TC, Shaaban AF, Radu A, Moseley AM, Deans R, Marshak DR, Flake AW. Human mesenchymal stem cells engraft and demonstrate site-specific differentiation after in utero transplantation in sheep. Nat Med 2000;6:1282-1286

19. Nagaya N, Fujii T, Iwase T, Ohgushi H, Itoh T, Uematsu $M$, Yamagishi $M$, Mori $H$, Kangawa $K$, Kitamura S. Intravenous administration of mesenchymal stem cells improves cardiac function in rats with acute myocardial infarction through angiogenesis and myogenesis. Am J Physiol Heart Circ Physiol 2004;287:H2670-H2676

20. Amado LC, Saliaris AP, Schuleri KH, St John M, Xie JS, Cattaneo S, Durand DJ, Fitton T, Kuang JQ, Stewart G, Lehrke S, Baumgartner WW, Martin BJ, Heldman AW, Hare JM. Cardiac repair with intramyocardial injection of allogeneic mesenchymal stem cells after myocardial infarction. Proc Natl Acad Sci U S A 2005;102:11474-11479

21. Terrovitis JV, Smith RR, Marbán E. Assessment and optimization of cell engraftment after transplantation into the heart. Circ Res 2010;106:479-494

22. Huang XP, Sun Z, Miyagi Y, McDonald Kinkaid H, Zhang L, Weisel RD, Li RK. Differentiation of allogeneic mesenchymal stem cells induces immunogenicity and limits their long-term benefits for myocardial repair. Circulation 2010; 122:2419-2429

23. de Almeida PE, van Rappard JR, Wu JC. In vivo bioluminescence for tracking cell fate and function. Am J Physiol Heart Circ Physiol 2011;301:H663-H671

24. Lionetti V, Bianchi G, Recchia FA, Ventura C. Control of autocrine and paracrine myocardial signals: an emerging therapeutic strategy in heart failure. Heart Fail Rev 2010; 15:531-542

25. Liang X, Ding Y, Zhang Y, Tse HF, Lian Q. Paracrine mechanisms of mesenchymal stem cell-based therapy: current status and perspectives. Cell Transplant 2014;23:10451059

26. Chimenti I, Smith RR, Li TS, Gerstenblith G, Messina E, Giacomello A, Marbán E. Relative roles of direct regeneration versus paracrine effects of human cardiosphere-derived cells transplanted into infarcted mice. Circ Res 2010; 106:971-980

27. Hare JM, Traverse JH, Henry TD, Dib N, Strumpf RK, Schulman SP, Gerstenblith G, DeMaria AN, Denktas AE, Gammon RS, Hermiller JB Jr, Reisman MA, Schaer GL, Sherman W. A randomized, double-blind, placebo-controlled, dose-escalation study of intravenous adult human mesenchymal stem cells (prochymal) after acute myocardial infarction. J Am Coll Cardiol 2009;54:2277-2286

28. Bilal M, Haseeb A, Sher Khan MA. Intracoronary infusion of Wharton's jelly-derived mesenchymal stem cells: a novel treatment in patients of acute myocardial infarction. J Pak Med Assoc 2015;65:1369

29. Gao LR, Chen Y, Zhang NK, Yang XL, Liu HL, Wang ZG, Yan XY, Wang Y, Zhu ZM, Li TC, Wang LH, Chen HY, Chen YD, Huang CL, Qu P, Yao C, Wang B, Chen GH, Wang ZM, Xu ZY, Bai J, Lu D, Shen YH, Guo F, Liu MY, Yang Y, Ding YC, Yang Y, Tian HT, Ding QA, Li LN, Yang XC, Hu X. Intracoronary infusion of Wharton's jelly-derived mesenchymal stem cells in acute myocardial infarction: double-blind, randomized controlled trial. BMC Med 2015;13:162

30. Musialek P, Mazurek A, Jarocha D, Tekieli L, Szot W, Kostkiewicz M, Banys RP, Urbanczyk M, Kadzielski A, Trystula M, Kijowski J, Zmudka K, Podolec P, Majka M. Myocardial regeneration strategy using Wharton's jelly mesenchymal stem cells as an off-the-shelf 'unlimited' therapeutic agent: results from the Acute Myocardial Infarction First-in-Man Study. Postepy Kardiol Interwencyjnej 2015; 11:100-107

31. Chou SH, Lin SZ, Kuo WW, Pai P, Lin JY, Lai CH, Kuo $\mathrm{CH}$, Lin KH, Tsai FJ, Huang CY. Mesenchymal stem cell 
insights: prospects in cardiovascular therapy. Cell Transplant 2014;23:513-529

32. Zhang Y, Liang X, Lian Q, Tse HF. Perspective and challenges of mesenchymal stem cells for cardiovascular regeneration. Expert Rev Cardiovasc Ther 2013;11:505-517

33. Tang Q, Chen Q, Lai X, Liu S, Chen Y, Zheng Z, Xie Q, Maldonado M, Cai Z, Qin S, Ho G, Ma L. Malignant transformation potentials of human umbilical cord mesenchymal stem cells both spontaneously and via 3-methycho- lanthrene induction. PLoS One 2013;8:e81844

34. Weiss ML, Anderson C, Medicetty S, Seshareddy KB, Weiss RJ, VanderWerff I, Troyer D, McIntosh KR. Immune properties of human umbilical cord Wharton's jelly-derived cells. Stem Cells 2008;26:2865-2874

35. Lohan P, Coleman CM, Murphy JM, Griffin MD, Ritter $\mathrm{T}$, Ryan AE. Changes in immunological profile of allogeneic mesenchymal stem cells after differentiation: should we be concerned? Stem Cell Res Ther 2014;5:99 